\title{
Salvage aorto-hepatic jump graft for hepatic artery thrombosis following living donor liver transplantation: a case report with 10-year follow-up
}

\author{
Shin Hwang, Jin Uk Cho, Chul-Soo Ahn, Deok-Bog Moon, Gil-Chun Park
}

Department of Surgery, Asan Medical Center, University of Ulsan College of Medicine, Seoul, Korea

Background: Hepatic artery thrombosis (HAT) following living donor liver transplantation (LDLT) is a lethal complication. We present the case of a patient who underwent salvage redo hepatic artery reconstruction using an aorto-hepatic jump graft because of HAT following LDLT.

Case report: A 64-year-old female patient diagnosed with hepatitis $C$ virus-associated liver cirrhosis and hepatocellular carcinoma underwent salvage LDLT using a modified right liver graft. Partial graft infarct was identified at posttransplant day 4, and by day 9 , it had spread. Celiac arteriography showed complete occlusion of the graft hepatic artery. We performed redo hepatic artery reconstruction using a fresh ilio-femoral artery homograft 10 days after the LDLT operation because such a vessel homograft was available at our institutional tissue bank. The infrarenal aorta was dissected and an ilio-femoral artery graft was anastomosed. Soon after hepatic artery revascularization, liver function progressively improved, and the infarct area at the liver graft was reduced. The patient has been doing well for 10 years without any vascular complications.

Conclusions: Our experience with this case suggests that salvage redo hepatic artery reconstruction using an aorto-hepatic jump graft is a feasible option to treat HAT following LDLT, as in deceased donor liver transplantation.

Corresponding author: Shin Hwang

E-mail: shwang@amc.seoul.kr

\section{(c) The Korean Society for Transplantation}

This is an Open Access article distributed under the terms of the Creative Commons Attribution Non-Commercial License (http://creativecommons.org/licenses/by-nc/4.0/) which permits unrestricted non-commercial use, distribution, and reproduction in any medium, provided the original work is properly cited. 